\title{
Thinking Process of Nursing Students' Clinical Judgment in Pediatric Nursing Practicum
}

\author{
Mari Okada1, Yuko Tomari² \\ ${ }^{1}$ Osaka Medical College Graduate School of Nursing, Osaka, Japan \\ ${ }^{2}$ Osaka Medical College, Osaka, Japan \\ Email:m.okada.t@aichi-kiwami.ac.jp
}

How to cite this paper: Okada, M. and Tomari, Y. (2017) Thinking Process of Nursing Students' Clinical Judgment in Pediatric Nursing Practicum. Open Journal of Nursing, 7, 1258-1273. https://doi.org/10.4236/ojn.2017.711091

Received: October 19, 2017

Accepted: November 18, 2017

Published: November 21, 2017

Copyright (c) 2017 by authors and Scientific Research Publishing Inc. This work is licensed under the Creative Commons Attribution International License (CC BY 4.0).

http://creativecommons.org/licenses/by/4.0/

(c) (i) Open Access

\begin{abstract}
This aim is to clarify thinking process of nursing students' clinical judgment, i.e., how nursing students act and think and what influences this thinking process of identifying approaches necessary for the children under their care in pediatric nursing practicum. By the analysis of M-GTA, students concurrently performed "A: Analytically contemplating the state of this child's body" and "B: Contextually contemplating this child's individuality". As a result, they acquired " $\mathrm{C}$ : Understanding of this child as a familiar existence." This allows students to enable them to " $\mathrm{D}$ : Identify the necessary approach using judgment criteria for this child." Furthermore, as situations that promote thinking by relating to all processes of thinking, students experienced "E: Attempts to solve problems through various measures" and "F: Encouragement of thinking through reflection." Meanwhile, "G: Stagnation of thinking because of concerning matters" inhibited the progress of thinking. We found a need for education after grasping the process of student thought.
\end{abstract}

\section{Keywords}

Pediatric Nursing Practicum, Nursing Students, Clinical Judgment, Thinking Process

\section{Introduction}

Developing the ability for clinical judgment, i.e., the identification of the approach is needed for the situation of a care recipient according to proper clinical reasoning, is an important task in basic nursing education. A variety of educational methods have been tried in both universities and clinical settings for training nurses in clinical judgment [1].

Tanner defines "clinical judgment" as "an interpretation or conclusion about 
a patient's needs, concerns, or health problems, and/or the decision to take action (or not), use or modify standard approaches, or improvise new ones as deemed appropriate by the patient's response" [2]. In the classroom, students learn how to develop clinical judgment, and in clinical training, students gather and interpret a variety of information on the patients they are evaluating to identify the suitable approach while making use of what they have already learned.

In their book "Teaching in Nursing," Diana et al. [3] discuss the need for clinical training in relation to students learning how to apply the knowledge and skills that they have acquired while simultaneously thinking critically to make clinical judgments. Benner et al. [4] also discuss the development of clinical reasoning and judgment in clinical situations. This demonstrates the importance of learning in clinical settings to develop a mindset for clinical judgment.

Clinical training is an opportunity to interact with real patients and to receive guidance from and directly observe professional nurses at work. Clinical training is also a chance to integrate theory with practice and to gain practical knowledge. Clinical instructors play a large role in this training. In her 2014 paper titled "Systematic Review of Clinical Judgment and Reasoning in Nursing," Cappelletti writes, "By improving ways to teach the development of these processes (clinical judgments and reasoning) in both nursing students and practicing nurses, nurses can learn to balance intuitive and evidence-based thinking to make moral and effective clinical decisions." She suggests that in this field of study, research is underway into the nature and methods of teaching of this skill [1]. This implies that there is significance to knowing the thought processes that students go through in practical settings to make clinical judgments, i.e., how they identify and choose approaches suited to the care recipient, so as to devise teaching methods for future practical training.

Clinical judgment is likely influenced by culture [1]. This paper is intended to offer suggestions for future educational interventions during clinical teaching by clarifying the process of how nursing students at Japanese universities make clinical judgments during practical training in which the students provide nursing care to a child for the first time. The reasons for choosing pediatric nursing as the study topic in this paper was the expertise of the researchers in this field, as well as the nature of this field as one in which students face difficulty and require knowledge-based thinking because of their inexperience in understanding the children under their care.

\section{Purpose}

To clarify how nursing students act and think and what influences this thinking in the process of identifying approaches necessary for the children under their care in pediatric nursing practicum.

\section{Methods}

\section{1) Participants}


The participants in this study were third-year students who had completed pediatric nursing practicum at universities of four-year nursing curriculum in Japan that agreed to cooperate in the study. The students were included in the study after completion of practical training and after receiving explanations regarding the study and providing their consent to participate.

\section{2) Method of data collection}

The data collection period is from October 2016 to February 2017. About one hour interview was conducted one by one for students who agreed in a room they could relax. The interview was done by the first author. The students were first asked to give their age as background information. The students were then asked about information on the child under their care, including the child's age, sex, disease, and course of hospitalization. The students were also asked to broadly describe the primary nursing care they provided during the practical training period. Afterward, the students were asked more detailed questions on their thoughts during practical training, such as "What do you believe you were able to improve in providing care to the child and his or her family? What did you think about your care in this practice? Why did you think that idea? What kind of information did you get, what did you observe? What did you refer to when doing?" and "Is there anything you have troubled with when you are in the care? Who did you talk about the trouble? How did you solve when you were in the trouble? What did you want to do more of that you were unable to do?" The students were asked how they acted and thought when providing this care. Examples included the reactions of the patient and his or her family, intervention by clinical instructors or teachers, conferences between students, and daily conversations.

\section{3) Method of data analysis}

We used the Modified Grounded Theory Approach (M-GTA) [5] [6] for the analytical method in this study. The Grounded Theory Approach is effective in analyzing dynamic social interactions and excellent in building unifying explanatory theories for phenomena. It was therefore considered a suitable analytical method for this study having the aim to clarify the thinking process of students that changes with the intertwining and mutual interaction of complex factors of practical training. M-GTA is a method developed by the Japanese sociologist Kinoshita, which is a revised and more practicable form of the Grounded Theory Approach proposed by Glaser and Strauss in the 1960s. M-GTA is a revised format that is easier to use in actual analyses in restricted fields, which makes it a valid analytical method in studies on students in which strict theoretical sampling is not feasible.

The details of the analytical method using M-GTA are as follows.

- At first, we decided an analytical focus group and the analytic theme according to research theme in this study.

The analytical focus group was "nursing students who had completed pediatric nursing practicum.” 
The analytical theme was "What do nursing students think and feel, and how do they act in the process of learning how to perform all the necessary observations and provide the necessary care to children? In addition, what influences this thought process?"

- Attention was paid to data related to this theme so as to perform open coding and generate concepts for each piece of semantic content.

- An analytic worksheet was created for each concept and continuous comparative analysis was performed to examine each example while recording the results as theoretical memos. This was done until no more new concepts could be generated.

- After that, categories formed of relationships among several concepts were generated and the analytical results were summarized according to the relationships among categories to create a results diagram.

- Analysis was done while holding discussions with researchers experienced in pediatric nursing and qualitative research as needed. Teachers with long-term working experience in pediatric nursing education were also asked for their opinions on the validity of the results, after which the results were modified accordingly to ensure the validity.

\section{4) Ethical considerations}

The institutional review board of Osaka Medical College gave their approval for this study to be conducted (approval number: KAN-31 [1931]). The students included in this study all received individual explanations of the study upon completion of practical training. The explanations covered the purpose and overview of the study. They clarified that participation was voluntary, the students were free to withdraw their participation at any time, acceptance or refusal to participate would not affect the students' grades, anonymity would be guaranteed, and that the study results would be presented at academic conferences and in papers. The students who agreed to participate were individually contacted to set a date and time for an interview and were assured that their decision to participate or not would not be disclosed to anyone other than the researchers. Personal information was securely stored in a keyed locker and data were only analyzed after anonymization.

\section{Results}

\section{1) Overview of the participants}

Four universities gave their approval for this study to be conducted and 26 students agreed to participate. Kinoshita (2003) suggested that the database of M-GTA would be from 10 to 20 cases [5], so we decided that 26 students agreed with were appropriate. All the students were women in their early 20s. All the students were engaged in practical training on a pediatric unit after having completed a seminar or practical training interacting with healthy children. The practical training on the unit lasted 6 - 10 days. At all the universities, the students were responsible for a single child each, and if this child was discharged, 
they continued their practical training to develop the nursing process with a different child.

\section{2) Analytical results}

Eighteen concepts were identified in the analysis and seven categories (A-G) were identified from similarities and relationships between concepts. The relationships between the categories are presented in Figure 1.

\section{a) Storyline}

The storyline is presented first. This is a comprehensive description of the relationships between categories identified from the data analysis. Students concurrently performed "A: Analytically contemplating the state of this child's body" and "B: Contextually contemplating this child's individuality". As a result, they acquired " $\mathrm{C}$ : Understanding of this child as a familiar existence." This allows students to enable them to " $D$ : Identify the necessary approach using judgment criteria for this child." Furthermore, as situations that promote thinking by relating to all processes of thinking, students experienced " $\mathrm{E}$ : Attempts to solve problems through various measures" and "F: Encouragement of thinking through reflection." Meanwhile, "G: Stagnation of thinking because of concerning matters" inhibited the progress of thinking. When thinking stagnated, $\mathrm{E}$ and $\mathrm{F}$ sometimes promoted thinking, or caused practical training to end without overcoming this stagnation.

b) Descriptions of categories and concepts

Descriptions and variations (case numbers) of the concepts forming each

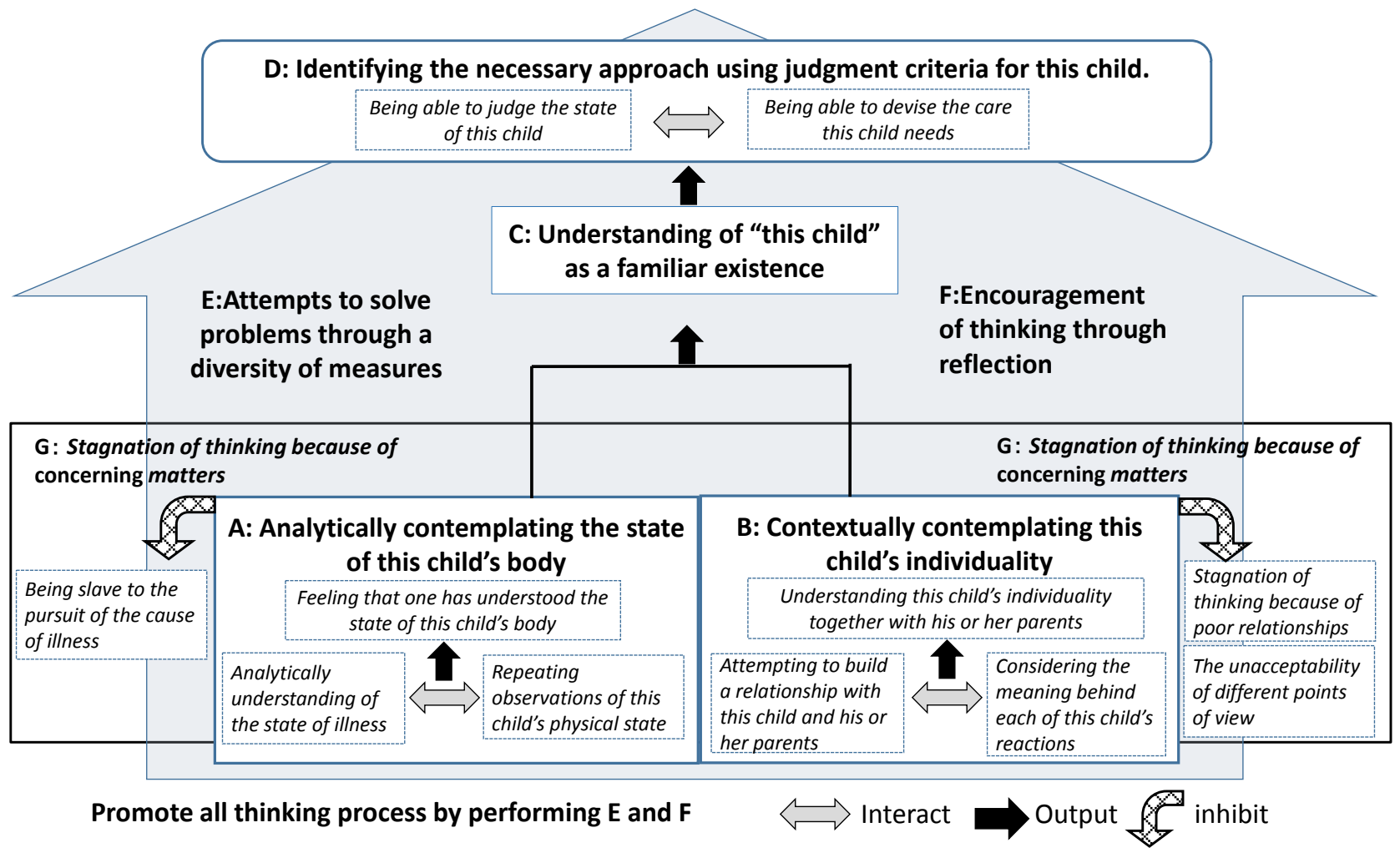

Figure 1. Thinking process of nursing students until finding the necessary approach for this child. 
category are presented in italics below.

\section{A: Analytically contemplating the state of this child s body}

This category is composed consists of three concepts: "Analytically understanding the state of illness," "Repeating observations of the child's physical state," and "Feeling that one has understood the state of this child's body." Interaction and repetition of understanding illness and clinical observation the state of the body led to more complete observations and an assuredness that they understood the state of the body.

\section{Analytically understanding of the state of illness}

Students connected matters they experienced for the first time in practical training with knowledge they had learned in theory. They also linked information obtained from medical records and personal observations to previous knowledge of the illness to develop an understanding of the state of illness of a child through the logical analysis of the disease etiology, symptoms, and significance of treatment.

In a child with Kawasaki disease, I wondered if what I was seeing was really membranous desquamation. I did not really know about this; so I asked my teacher to explain it to me. (Case 10)

The pathology was really difficult to understand. This child had three surgeries. I examined the disease first. But, I could not understand at all. I started to understand the purpose and other aspects of the surgery by reading medical books and other references. From there, I started studying by making connections with the pathology. (Case 24)

\section{Repeating observations of this child s physical state}

At first, students began to perform general, textbook observations and reporting these to clinical instructors and teachers, and received their guidance and learned. Based on information obtained from observation and learning, they analytically contemplated children's physical states several time and reconsidered the observation items. By repeating the observation and analysis, they acquired the necessary observation item to know the state of the body.

My instructor asked me, "Do you only check for a fever when checking for infection?" When I answered that I check for a fever, runny nose and cough, my instructor then asked, "What are the risks of infection?" To which I answered, "Interstitial pneumonia." This prompted the question, "What are the symptoms of interstitial pneumonia?" My reply was " $A$ dry cough and audible crackling chest sound," to which my instructor responded with "So, you have to look for that." This steadily increased the number of observations and became more detailed. (Case 2)

\section{Feeling that one has understood the state of this child $s$ body}

In the process of repeating observation and analysis, students developed an understanding of the relationship between their knowledge and the information they obtain, and between bits of information themselves. Students felt that scattered information became "connected" and from the necessary information 
developed the feeling that they had understood the physical state of the child under their care.

In my mind, various pieces of information appeared to be connected like an equation. When a person develops leukemia, this causes myelosuppression, and when leukocytes decrease in test data, immunity drops. This led me to understand that decreased immunity makes a person more susceptible to infection. (Case 1)

When I began wondering why this child was incapable of auto-expectoration, and when I was told that the child was unable to cough effectively, I went back to my textbooks on pediatric medicine again to look into the respiratory organs. This helped me make the connection that the child's organs were undeveloped to begin with, and not that another muscle in the child had deteriorated or something like that. (Case 9)

\section{$B$ : Contextually contemplating this child s individuality}

This category consists of three concepts: "Attempting to build a relationship with this child and his or her parents," "Considering the meaning behind each of this child's reactions," and "Understanding this child's individuality together with his or her parents."Cumulative consideration of the meaning behind each reaction in interactions with the child and his or her parents led to an understanding of the child's individuality.

\section{Attempting to build a relationship with this child and his or her parents}

Students considered building a relationship with a child and his or her parents was important for providing nursing care. That is why students attempted to build a relationship by utilizing their knowledge of development and by employing their own communication methods.

I believed that I would not be able to obtain any available information if I did not build a relationship of trust. So, to build a relationship with this adolescent child, I started by talking for a bit about random things and was then able to ask the child about their feelings on their illness. (Case 1)

The family of this child told me that the child began to learn words because various people had come to talk to them after they arrived at the hospital. So, I thought that I would also make an effort to talk to the child. Because the child liked cars, I would say, "It's a fire engine" or "They're putting out the fire." The child was at a stage in which they might have been able to speak one or two-word sentences, so I made an effort to speak in simple sentences of a few words using nouns as much as possible. (Case 2)

\section{Considering the meaning behind each of this child s reactions}

Students tried to interpret the meaning of the child's reactions at every opportunity by watching them as observers of care situations, and in their own involvement with the child. They also referred to the parents' opinions, the advices of teachers and instructors, and to their own knowledge on child development in understanding their reactions.

The child was different from my mental image of a 6-year-old. During being 
hospitalized, the boy was in continuous motion; slapping people on the bottom; licking people's hands. I saw the mischievous side of him. I wondered if he lacked concentration or had a low level of comprehension. But when I gave him a quiz on his illness, he chose all the right answers. He was actually a child with good comprehension and concentration, but I think he might have become pretty naughty because he was unable to play with friends because of his hospitalization or because of the stress of not being able to move about. (Case 6)

It was difficult because I was totally unable to read the expressions of this 4-month-old child. When the child cried, I tried hard on thinking what I had done wrong. (Case 8)

Understanding this child s individuality together with his or her parents

While looking for meaning behind the reactions of the child and building a relationship with the child and his or her parents, students discovered the individuality of the child, such as his or her personality, way of thinking and developmental characteristics. Students also felt that to children, parents were an indispensable existence. Students were also able to perceive the characteristics of the parents from the perspective of the child who was together with them.

I learned the developmental theories of Erikson and Piaget, but there is a considerable difference, and while I reference these theories, they are merely guidelines. I realized that I really had to look at each child to determine what developmental stage he or she was in. (Case 21)

In the case of this child (with severe physical and mental disability), I strongly felt that the mother was bearing the burden alone and she appeared to be exhausted. That's because I saw the mother spontaneously dozing off many times. (Case 22)

\section{C: Understanding of "this child" as a familiar existence}

This category consists of one concept: "Shortening of the sense of distance between oneself and this child." By developing an understanding of the child's physical state and individuality, a clear image of "this child" was formed, which led to the understanding of the child as a familiar existence.

Shortening of the sense of distance between oneself and this child

By developing an understanding of the child's physical state and individuality, students felt that the psychological gap between themselves and the child became less.

He was at an age at which he could start talking on his own; so as I talked about various things, the child steadily became better at talking, the distance between us really decreased. (Case 10)

By understanding why there was a risk of heart failure, I really started to see the patient clearly. At first, it felt like, "What should I do? What should I do? I don't understand the heart at all." By knowing what state this child is in, I felt that I had become closer to him. At first, I really felt a sense of distance. (Case 5)

$D$ : Identifying the necessary approach using judgment criteria for this child 
This category consists of two concepts: "Being able to judge the state of this child" and "Being able to devise the care this child needs." Students provide care that they judge necessary according to the child's state. In repeating this process of re-judging a child's state after providing care, students developed an understanding of the judgment criteria for the child, and used these judgment criteria to identify necessary approaches for the child.

Being able to judge the state of this child

Through the process of identifying the child's physical state and individuality, students were able to acquire judgment criteria to help understand and to properly judge the child's current state.

I looked at the child's status last night to check if he had experienced vomiting, had been able to sleep well, or had developed a fever. I am now able to check medical records and properly evaluate at the child, including his expression, to see if he is calm when I meet in the morning. The judgment criteria have increased day by day. (Case 8)

Being able to devise the care this child needs

Students used judgment criteria to judge the child's state and devised care methods tailored to the child's present situation and required care.

What causes the child pain is the pulling of the muscles when the child bend their knees; so I reassured the child by saying "I ll keep a firm hold of you here." I lend assistance by ensuring that absolutely no pain spreads there. (Case 15)

The child lost the ability to stand after becoming ill; so I thought to help the child increasing the activity level, such as by crawling, in large open spaces. But because of the risks, I made sure to support the child from behind to prevent falling. (Case 2)

\section{E: Attempts to solve problems through a diversity of measures}

This category consists of three concepts: "Making an effort to learn for the sake of this child," "Seeking advice from others," and "Obtaining hints from teachers' and nursing staff's suggestions and behaviors." Students tried to adopt a variety of measures because of limitations with their own capabilities to solve their problems. This category represents the promotion of thinking associated with all processes seen at all stages from A to D.

\section{Making an effort to learn for this child}

Students made an effort to independently continue learning for providing nursing care to the child under their care, such as by re-learning and improving their basic knowledge to understand the child's illness, double-checking their knowledge to verify their own understanding, and devising care methods by utilizing previously acquired knowledge.

We had to do preparatory studies in which we were given some diseases and had to prepare summaries of them, but it was fairly superficial. When I actually had a patient under my care and asked myself what I could for this child, I realized that what I already knew was not enough, and I studied a lot more." (Case 5) 


\section{Seeking advice from others}

When students were unable to find solutions on their own, they sought the advice of others. Students made an effort to personally solve problems by asking teachers and nurses' questions, seeking explanations, and seeking the opinions of fellow students.

During conferences, I talked about what I had struggled with and shared information with everyone else, the idea was to share any suggestions we might have. During one conference, a group member gave this suggestion... I thought "This is how it should be done." (Case 7)

I was at a loss (because a child was exhibiting rejective behavior). Because I liked a child, the rejection really hurt me and made me depressed. I consulted my teacher about this. (Case 22)

Obtaining hints from teachers' and nursing staff s suggestions and behaviors

Teacher and clinical instructors asked various questions to encourage more thorough understanding in students, and worked with them to explain and verify any points that students were unsure of. Students used these words as hints to deepen their understanding by re-examining and reconsidering their knowledge. Students also obtained hints from patient status descriptions by medical staff around them and from observing the care provided by nurses.

My teacher really dug deep down by repeatedly asking questions like "What about this? What about this?" So I noticed a lot of things. I realized that I might have been thinking too negatively and that recognizing this was a good thing for the child. (Case 22)

A nurse in the pediatric unit was really good at finding the words to motivate patients... I realized that detailed explanations were necessary. (Case 7)

The rehabilitation instructor told me to think about how to support my patient in walking safely instead of not allowing my patient to walk because it is dangerous. She told me to come up with standing positions and methods of support, which really gave me an opportunity to think. (Case 12)

\section{F. Encouragement of thinking through reflection}

This category consists of three concepts: "Evaluating one's care from this child's and his or her parents' reactions," "Gaining confidence through the support of others" and "Reflecting on one's actions and thinking." Students advanced their reasoning in all scenes using self-reflection to reconsider their care methods and to turn over their own feelings. When performing reflection, the reactions of the child and his or her parents and the support from others became indices for students to evaluate their own actions and thinking. Obtaining validation for these actions and thought encouraged thinking.

\section{Evaluating one's care from this child's and his or her parents' reactions}

Students used the reactions of children and their parents during care as hints to evaluate their own care and modify subsequent approaches according to this evaluation.

When I chose a coloring book about the child s favorite character, the child 
was really pleased and I gave loads of these coloring books to his mother. The next day, when the child was throwing a bit of a tantrum, his mother gave him the coloring book and the child cheered up. She said to me "Thank you very much." Because the children have limitations in what they can do, I thought that offering the child something like that was good idea. (Case 21)

Gaining confidence through the support of others

At times, students did not have confidence in their own thought and actions; however, the support from teachers and group members, who commented that students' thinking and actions were good, gave the students confidence to move ahead with their thinking and actions.

I was really worried that the child might hate me, but my teacher said to me, "I think you have built a good rapport," which made me think that I handled it in the right way after all. (Case 7)

Reflecting on one's actions and thinking

Students reflected on their actions and thinking in various scenes, including their own observations, communication, and care, either personally or together with teachers and group members. Reflection sometimes led students to modify their actions and thinking and other times to merely end at self-contemplation. Furthermore, when students felt hesitant in their relationships with children, they considered matters from the perspective of the child and switched to focusing their thoughts on the need to support the child. At a result, they moved ahead with their thinking and actions.

I thought I had failed when I brought the board game Othello to play with; it unfortunately took time (to reverse the pieces) because of the paralysis. Even from their perspective, I thought it must have been boring, it ended up being like rehabilitation. It wasn't that great I guess. (Case 17)

It was difficult to know what was right, or what was demanded by this child unable to express himself. However, I felt that I absolutely had to take action as a nurse. I believed that it was important to act with the understanding that doing so leads to the safety and comfort of the child. (Case 8)

\section{G. Stagnation of thinking because of concerning matters}

This category consists of three concepts: "Being slave to the pursuit of the cause of illness," "Stagnation of thinking because of poor relationships," and "The unacceptability of different points of view." These situations inhibited the progression of thinking. On some occasions, these situations were suddenly resolved and thinking progressed, while on other occasions, students were unable to find a solution and ended practical training unable to accept the outcome.

\section{Being slave to the pursuit of the cause of illness}

Students sometimes felt the desire to clearly know the factors behind a child's current symptoms that had solidified over the long course of treatment, or even the cause of the illness under examination, for understanding the pathology and treatment. However, the cause of a child's condition sometimes remained medically unclear because of data gathering limitations and details that could not be 
investigated in general literature. Although the students could still provide nursing care without this data, they were slave to their desire to know and investigate the child's condition, which sometimes led to conflicted feelings over the need to dig deeper and stagnated thinking.

(The cause) of quadriplegia can be cerebral palsy or cervical spinal cord injury, but I wanted to ask which it was, if it was indeed clear. The specifics were not written in the medical records. Even when I asked my instructor, they did not appear to be certain, and either way, the fact that this child was paralyzed wasn't going to change, and neither was it going to change the nursing care that I provided... (Case 17)

\section{Stagnation of thinking because of poor relationships}

When the child was rejective and relationship building was difficult, students were at a loss, felt depressed and were unable to act despite being able to think. In some cases, students no longer knew what to do, which led to stagnation of thinking.

Im told pretty dismissive things, such as "Go away." They have said things like, "P d like to cancel," which hurt me and made me refrain from going. When I consulted my teacher, she said, "Perhaps he is testing you; so try observing him when he says something dismissive"... (Case 6)

The unacceptability of different points of view

When it came to points of view on the child's personality and developmental characteristics, the opinions of students and teachers could clash and students were sometimes unable to accept teachers' or instructors' explanations. When this happened, students inhibited thinking in a situation which they couldn't find a clear answer.

I couldn't accept my teacher's opinion. In my interactions with this child, I saw that the child could study at a level commensurate with their age and was looking after a younger child; I thought the child was a proper normally developing child. However, my teacher saw things differently. She said, "Isn't that child a little mentally immature?" I hadn't noticed that, which was, how would you say, a little painfur? I replied, "I don't think that's true" and gave an example of a specific situation. The teacher appeared to question my opinion. (Case 13)

\section{Discussion}

The results of this study revealed that the objective of the clinical judgment thinking process of students is to "identify the approach necessary for this child by using judgment criteria for this child," and that students employed analytical and contextual thinking about the child under their care. This section discusses the aspects of thinking leading up to this objective, and circumstances of students in relation to the promotion and inhibition of the thinking process.

1) Aspects of thinking to identify the approach necessary for this child while simultaneously progressing with analytical and contextual thinking

The results of the analysis revealed that students judged the situation of a 
child while simultaneously performing analytical thinking to understand the child's physical state and contextual thinking to understand the child's individuality. Tanner suggests that "analytic," "intuitive," and "narrative" reasoning patterns exist in the clinical judgment of nurses. She also writes that less experienced nurses compare patients' symptoms with textbook cases while carefully examining data from textbooks and assessments [2]. Students are also beginners who begin by analytically understanding the situations of patients by comparing knowledge from textbooks. While experienced nurses are capable of instantaneous analytic judgment according to practical knowledge acquired from practice, students have little experience, which requires them to use scientifically proven knowledge to connect and understand underlying evidence and specific patient data. Students learn from this process of connection, and as symbolized by the expression "connected like an equation," ascertain a child's physical state while experimentally learning about analytically and logically built thinking.

On the other hand, the contextual thinking in this study may be synonymous with "narrative reasoning" coined by Tanner. The students in this study ascertained the characteristics of children as "this child's individuality," which they interpreted on the basis of a temporal axis and relationships from sources, including the child's reactions and information from the parents. Unlike analytical thinking to understand a child's physical state, students utilize knowledge on development as a guideline to interpret the unique individuality of each child from their reactions as needed, instead of connecting knowledge on development with the child's situation. These two simultaneous thinking processes are not consciously differentiated and used by students but rather are different ways of utilizing knowledge in the understanding of children, the learning of which is characterized by students' remarks such as "I thought that developmental theory was a guideline."

By proceeding with these two thinking processes in parallel, students developed an understanding that made them feel close to the child under their care. However, this is not simply a process of becoming close with a child after building a relationship. It is the sense of closeness that arises when a child that was once difficult to understand becomes an existence that the students can properly picture in front of them in their minds. This can also be described as a characteristic of child understanding. Unlike with adults, students have fewer opportunities to interact with children and find it extremely difficult in caring for these mostly unfamiliar, sick children [7]. Students can also feel anxious about building a relationship. Other studies have also revealed that students develop a sense of closeness with children through a combination of directly deepening their relationship and understanding the illness and characteristics of the child. Takahashi et al. (2012) refer to this as "sense of connection with the children" [8]. Closeness that comes from building an actual relationship is also important, but closeness from thinking too is important in furthering understanding of children. 
The ability that students gained through these two simultaneous thinking processes was to "identify the necessary approach using judgment criteria for this child." The thinking that takes place until students develop judgment criteria is obtained from experiential learning in clinical training; it is the acquisition of thinking methods for nursing tailored to the situations of individual patients.

2) Circumstances of students related to the promotion and inhibition of thinking processes in clinical judgment

Factors such as students' actions and emotions that promote and inhibit thinking were related to the advancement of thinking by students. One of the circumstances promoting thinking are the efforts made by students to resolve problems by attempting various measures, whereas another is the promotion of thinking through reflection.

Practical training is different from classroom learning in that the presence of a child to care for enhances the student's motivation to learn, triggers efforts to proactively learn, and promotes thinking. This is similar to Kagawa et al.'s (2007) suggestion that the change from motivation for classroom learning to motivation for learning in clinical training lies in the change of meaning from "learning for the sake of oneself" to "learning for the sake others" [9]. This points to the importance of motivation to learn for the sake of the child receiving care.

In addition to being places where a variety of professionals work, practical training settings provide students with stimulation for thinking amidst the interactions with numerous people and the large influence of nursing staff and group members. Knowing what they are learning and whom they are learning from is therefore an important step to students in understanding the thinking process in practical training settings. Cappelletti writes that "education strategies to improve clinical judgment may influence what a nurse brings to the situation" [1]. The involvement of professionals in situations in which students are required to make judgments therefore has a major influence on the thinking of students. In situations where students analytically think about a patient's physical state, properly reconciling scientifically proven knowledge or theory with actual situations is important; however, by demonstrating how knowledgeable professionals should think, students develop the ability to think current situations. Furthermore, the identification of important pieces of information from among a large amount of information, or deciding how to use what foundational knowledge to develop an understanding, is difficult for students to judge. The presence of professionals to demonstrate how to connect information in accordance with the student's level of understanding therefore promotes thinking.

Meanwhile, unlike analytical thinking, in which where the foundational knowledge is relatively clear, contextual thinking that encourages understanding of a child's individuality is influenced by factors, including a person's unique values, experience, and awareness, and is presumably difficult for students to understand. That is why experienced professionals demonstrating how to infer 
meaning from a child's characteristics and reactions are helpful to students' thinking as sources of practical wisdom. In some cases, however, inexperienced students have been unable to understand or even accept the meaning behind this thinking. Students' understanding of children requires intervention that embodies the process of thinking from a student's own experiences and from contextual interpretation. The guidance given to them shall thus promote problem-solving that students should acquire, at the level and on content best suited to their current capacities.

Reflection was also useful for promoting thinking. In his reflective practice, Schön (1983) wrote that reflection performs both on and after actions and that properly supporting this reflection was important [10]. Ascertaining the aspects of students' reflection may therefore also be useful to the promotion of thinking. The results of the present study showed that reflection sometimes provided hints for subsequent actions; however, at other times reflection merely ended with confusion in students over how to evaluate their own actions. By forcing awareness of matters that should be reflected on, thinking was promoted and modifications were made to subsequent care, which suggests that teachers must offer guidance that ensures thinking is helpful to clinical judgment by properly recognizing students' confusion.

The results of the present study also showed circumstances of students that inhibit thinking. Students' circumstances in which they were slave to the pursuit of the cause of illness, had poor relationships with children, and experienced stagnated thinking because of factors, including the inability to accept different points of view likely influenced thinking because students' inexperience led them to concentrate on their own emotions. However, the presence of content on reflection to overcome these emotions by thinking from the child's perspective indicates the need to guide students toward promoting thinking while reflecting on their emotions.

\section{Conclusions}

1) By simultaneously moving ahead with both analytic and contextual reasoning, students become closer to and understand the child under their care and can identify the necessary approach using judgment criteria for the child.

2) The teachers and instructors who guide practical training must ascertain the reasoning processes of students and perform educational interventions tailored to these reasoning processes.

\section{Limitations of This Study}

Since this study was targeted to female students in their early twenties as the most common subjects as nursing students, it is considered that generalization is possible. However, this study does not consider the influence by the teaching skills. Teacher's guidance greatly influences students' thinking, so it is necessary to continue research on the influence of teaching skills. 


\section{Acknowledgements}

Thanks to students who participated in this study, Professor Junko Takemura, Professor Chiharu Akazawa, Professor Kumi Suzuki, and members of Pediatric seminar who gave us opinions on this study.

\section{References}

[1] Cappelletti, A., Engel, J.K. and Prentice, D. (2014) Systematic Review of Clinical Judgment and Reasoning in Nursing. Journal of Nursing Education, 53, 453-458. https://doi.org/10.3928/01484834-20140724-01

[2] Tanner, C.A. (2006) Thinking Like a Nurse: A Research-Based Model of Clinical Judgment in Nursing. Journal of Nursing Education, 45, 204-211.

[3] Billings, D.M. and Halstead, J.A. (2015) Teaching in Nursing-E-Book: A Guide for Teacher. Elsevier Health Sciences, St. Louis.

[4] Benner, P., Sutphen, M.L., Leonard, V. and Day, L. (2010) Educating Nurses: A Call for Radical Transformation. Jossey-Bass, San Francisco.

[5] Kinoshita, Y. (2003) Modified Grounded Theory Approach. The Practice of the Grounded Theory Approach. Kobundo, Tokyo. (In Japanese)

[6] Kinoshita, Y.Q\&A on M-GTA. The Japanese Society of M-GTA. http://m-gta.jp/en/qa.html

[7] Nishida, M. and Kitajima, Y. (2005) Process during Perceived of Students and Coping of Students in Clinical Training of Pediatric Nursing. Japanese Journal of Nursing Research, 28, 59-65.

[8] Takahashi, Y., Omi, S. and Miyagishima, K. (2012) The Process by Which Students Can Learn How to Provide Nursing Care from the Children's Point of View. Journal of Japan Academy of Nursing Science, 32, 35-44. https://doi.org/10.5630/jans.32.3_35

[9] Kagawa, S. and Sakurai, T. (2007) Nurse Students' Change of Learning in Process form Classroom to Nursing Clinical Course: The Analysis Based on Concept of "Transition" in Situated Learning Theory. Japanese Journal of Nursing Research, 30, 39-51.

[10] Schon, D.A. (1983) The Reflective Practitioner: How Professionals Think in Action (Vol. 5126). Basic Books, New York. 